Cad.Est.Ling., Campinas, 47(1) e (2):159-166, 2005

\title{
INTERACIONISMO, AFASIA E CLÍNICA DE LINGUAGEM
}

\author{
SUZANA CARIELO DA FONSECA \\ (Derdic, Pontifícia Universidade Católica-SP)
}

\begin{abstract}
This paper discusses the relationship between Language Acquisition and Language Clinic, i.e., between Cláudia de Lemos's theoretical proposal and reflections carried out by researchers who belong to the project "Language Acquisition and Language Pathology", supervised by Maria Francisca Lier-De Vitto at LAEL-PUCSP. The discussion focuses on clinical issues concerning aphasia.
\end{abstract}

A filiação ao Interacionismo proposto por Cláudia Lemos propiciou-me um assento, um posto de reflexão que me permitiu (e tem permitido) o levantamento e o encaminhamento de questões teórico-clínicas sobre a afasia: condição sintomática que se manifesta na fala e que tem me interrogado desde que, em 1988, quando atendi meu primeiro paciente afásico. Pode-se dizer mesmo que a referida proposta tornou-se um "instrumento de leitura" (Pêcheux, 1969) para os pesquisadores que, como eu, estão vinculados ao Projeto Aquisição da Linguagem e Patologia da Linguagem, coordenado pela professora Maria Francisca Lier-De Vitto, no LAEL-PUC/SP. Digo isso porque levo em conta o modo de aproximação entre essas áreas: falar em "instrumento de leitura” é assumir que o Interacionismo é invocado "não [...] para dar respostas mas para colocar questões” (P. Henry, 1990: 36)1.

Cabe esclarecer, então, que as proposições de base desse Interacionismo movimentam a investigação sobre as patologias e a clínica de linguagem que, em sua especificidade, exige que se leve em conta uma diferença fundamental: a dimensão de um sofrimento, ou seja, da presença de sintoma na fala. Entendo, como Rubinstein, que "sintoma é um conceito que nos instala diretamente no campo da clínica” (1966: 13). Sendo assim, é preciso considerar, nessa filiação, a diferença relativa à natureza do material a investigar e o exercício particular de uma clínica. No âmbito do Projeto, o contorno teórico que se procura dar às patologias da linguagem implica essa dupla condição que, por sua vez, imbrica acontecimento e clínica - espaço de acolhimento daquele que sofre por efeito de uma fala sintomática.

\footnotetext{
${ }^{1} \mathrm{O}$ que quero dizer é que o termo "filiação" diz de um movimento de aproximação em que proposições de base são compartilhadas sem perder de vista a especificidade da investigação. As questões suscitadas pela fala patológica exigem que diferenças sejam sustentadas.
} 
O que farei, a seguir, é uma discussão que, espero, esclareça o caráter relevante desse movimento de aproximação ao Interacionismo, levando em conta seus desdobramentos na investigação que tenho realizado sobre a afasia.

A estrutura básica da discussão que empreendi no mestrado - Afasia: a fala em sofrimento (1995) - pode ser resumida a partir de dois eixos centrais: o primeiro, refere-se à análise crítica que realizei do discurso organicista sobre a afasia e, o segundo, configura uma tentativa de abordar lingüisticamente a fala afásica. No que concerne ao primeiro, as bases da referida crítica estão em consonância com a questão, levantada por Lemos, acerca da complexa relação entre domínios heterogêneos. Como se sabe, nos primeiros tempos da proposta, essa questão estava vinculada à discussão que culminou na recusa de explicações para o lingüístico que implicavam a remissão a um "fora" da linguagem. Recusa que ganhou contorno teórico consistente quando, a partir de 1992, a noção de "língua" - e sua ordem própria de funcionamento - foi invocada para explicar o processo de aquisição da linguagem ${ }^{2}$. Portanto, a proposição formulada por Cláudia Lemos que estava no pano de fundo de minha reflexão sobre a afasia era: "uma explicação lingüística para o lingüístico". Vejamos como ela foi movimentada na análise do discurso organicista sobre a afasia.

Uma definição da afasia comumente aceita por clínicos e investigadores é a de que ela é "a perda ou perturbação da linguagem causada por lesão cerebral" (Benson \& Ardila, 1996: 3) (grifo meu). De fato, o ponto de convergência entre eles é a assunção de uma relação de causalidade entre cérebro e linguagem. Baseada na sucessão temporal dos eventos que remetem à afasia, qual seja, lesão cerebral $\rightarrow$ sintoma na linguagem, a lesão cerebral (acontecimento antecedente), é admitida, pelos médicos-pesquisadores, como "causa" da perturbação no lingüístico (acontecimento subseqüente). Sustentei, no referido trabalho, que esse raciocínio causal promoveu, no espaço da Medicina, a naturalização da relação cérebro $\rightarrow$ linguagem (e da linguagem!), dado o submetimento do lingüístico ao funcionamento cerebral. Como na Neurologia o cérebro é o objeto mistério a investigar -, a linguagem (sua ordem própria) resultou desproblematizada, foi reduzida a mero sinal, i.e, a comportamento desviante e motivado (desadaptado).

Note-se que a afasiologia foi historicamente edificada com base na sustentação dessa causalidade. Entretanto, pude também constatar que, no âmbito dos estudos médicos, alguns trabalhos já se ofereciam como "ilhas de resistência" à adoção desse princípio. Destaquei, na referida dissertação, a monografia de Freud (a partir de Jackson), A afasia. Tomei-a como exemplar de uma visão alternativa e revolucionária. Isso porque a discussão por ele encaminhada, abala a proposição-eixo do discurso organicista e coloca em xeque sua articulação lógica. Ao postular um "aparelho de linguagem", na qualidade de "concomitante dependente" (1891/1987: 70), cujo funcionamento não pode ser reduzido ao funcionamento cerebral, Freud estabelece um paralelismo entre duas ordens distintas de funcionamento: o "cerebral" e o do "aparelho da linguagem". O ponto nodal e subversivo da visada de Freud é o seguinte: "como estabelecer causalidade entre eventos que remetem

${ }^{2}$ Ver Lemos, C. T. G. (1992, 1995, 1996, 2002, entre outros). 
Cadernos de Estudos Lingüísticos 47(1) e (2) - Jan./Dez. 2005

a duas ordens de funcionamento paralelas?'. Romper com a noção de causalidade mecânica, sustentada no discurso organicista sobre a afasia, foi, para ele, a saída para uma outra explicação acerca do sintoma lingüístico, via postulação do funcionamento de um "aparelho da linguagem".

Eu entendi que o gesto de Freud indicava uma direção instigante: para discutir a afasia sob um ponto de vista lingüístico, parecia preciso romper com os parâmetros do discurso organicista. Como assinalou Freud, o dispositivo teórico invocado para dar conta do sintoma na linguagem deveria ser aquele que envolve hipóteses sobre o lingüístico sobre o "aparelho da linguagem." Assumir esse compromisso pareceu-me imperativo. Ressaltei que, nem por isso, seria preciso recusar a relação misteriosa entre cérebro e linguagem. Note-se, também, que pela via da discussão da relação cérebro-linguagem pude explorar as consequiências do raciocínio causal que envolve domínios heterogêneos e chegar a uma conclusão que fazia render a proposição de Lemos: "uma explicação lingüística para o lingüístico".

Se a releitura de Saussure e Jakobson, realizada por Cláudia Lemos (1992, 1995), produziu seus efeitos na reflexão sobre a causalidade, não foi outra a base sobre a qual se apoiou a análise que realizei da fala de dois afásicos. De fato, sua releitura iluminou o funcionamento da língua na fala desses sujeitos ${ }^{3}$, o que possibilitou uma abertura de olhar e de escuta: o sintoma na afasia ultrapassou, para mim, o estatuto de sinal (comportamento observável) de um acontecimento cerebral. Isso porque trazer a ordem própria da língua, suas leis de referência interna, permitiu que eu chegasse mais perto da "lógica que comanda a sintaxe de uma fala" (Lier-De Vitto, 2002e) e possibilitou tocar o mistério que a afasia coloca para um fonoaudiólogo.

Pelo viés da articulação língua-fala-sujeito ${ }^{4}$, pude discernir o modo singular de articulação da língua na fala dos pacientes afásicos e o modo - não menos singular de relação dos mesmos com a fala (própria e dos outros). A conclusão maior desse meu percurso pelo mestrado foi, portanto, o encontro com uma primeira convicção: a de que a afasia, para um fonoaudiólogo, é um problema lingüístico ${ }^{5}$. Certeza que resultou na necessária ruptura com o discurso organicista da causalidade lesão-sintoma.

Duas conclusões que abriram novas e muitas questões, entre as quais destaco: se a afasia é um problema lingüístico, ela concerne à clínica de linguagem. Mas, que sentido tem, para um clínico, o uso do termo "lingüístico" na definição da afasia? Uma questão que foi levantada por Lemos, num dos exames de qualificação da minha tese de doutorado

${ }^{3}$ Entender a fala (sintomática ou não) como produto do funcionamento da língua (um sistema cujas leis foram postuladas por Saussure (1916) e ampliadas por Jakobson (1954)) foi a base sobre a qual, então, eu pude propor que se tomasse a afasia como um problema lingüístico. Só que fala implica um falante. Incluí-lo na reflexão é uma exigência incontornável para quem, além de tudo, tem que falar de clínica. Ora, articular línguafala-falante é o empreendimento que tem marcado a investigação no campo do Interacionismo Brasileiro (seja na Aquisição da Linguagem ou na Patologia da Linguagem).

${ }^{4}$ Proposta pelo Interacionismo em Aquisição da Linguagem para explicar as diferentes posições de falante da criança (ver Lemos, 1995; Lier-De Vitto, 1995, entre outros).

${ }^{5}$ Como se vê, também, na esteira do que disse Jakobson (1954). 
e que encaminhei do seguinte modo: a insistência em dizer que a afasia é problema lingüístico vem para marcar posição em relação aos trabalhos do campo da afasiologia (neurológica ou fonoaudiológica) que desproblematizam a linguagem e, de fato, recuam todo conhecimento elaborado no campo da Lingüística. Entendo que não se pode abordar a afasia sem implicá-lo mesmo que, ao implicá-lo, se tenha que empreender o esforço teórico de, na consideração sobre o lingüístico, não deixar de fora o sujeito. Não é, portanto, o "lingüístico" stricto sensu que faz presença neste meu último trabalho.

Trabalho que representa um movimento de retorno à clínica já que, no mestrado, o meu caminho foi da inquietação da clínica para o enfrentamento teórico da afasia e das falas afásicas. O doutorado constitui-se, então, na aposta da articulação entre teoria e prática. Mais, particularmente, acreditei na viabilização de uma teoria da técnica no campo da linguagem. Não é sem razão que uma das primeiras questões que pude situar foi assim enunciada: "a idéia de clínica, de processo terapêutico propriamente dito, coloca irremediavelmente no foco da discussão a questão da mudança” (2002: 9). Questão que, também, dá vida à área de Aquisição da Linguagem. O que se colocava como exigência, então, era um discernimento: qual a sua especificidade no campo das patologias e clínica de linguagem?

Enfrentá-la significaria, por exemplo, considerar que pensar em mudança no interior desse campo dá margem a um raciocínio causal: afinal, na prática clínica, o que está em foco é a implementação de procedimentos que visem a transformação do sintoma. Deveria eu, então, que havia debatido e recusado a noção de causalidade para pensar falas afásicas, ressuscitar o pensamento causal para pensar a clínica? Paradoxo ... Encruzilhada ... Impasse que remete à problemática da relação teoria-prática e que respondeu pela elaboração do doutorado.

Reconhecendo a centralidade da problemática da causalidade na afasia (e na clínica da afasia) coloquei-a, mais uma vez, em perspectiva. Revisitei propostas no campo da Medicina e da Fonoaudiologia para examinar, agora, a consistência entre discussão teórica e exercício clínico. Nesse movimento que vai de teorizações à clínica, concluí que se a relação dos médicos - Freud $(1891)$ e Jackson $(1866,1884)$ - à Filosofia mobilizou questões importantes, mais especificamente, a desnaturalização da noção de causalidade e uma certa autonomia do lingüístico - que se expressa no paralelismo psicofísico -, a relação de Goldstein $(1933,1948)$ e Luria $(1947,1974)$ à Psicologia recua esses avanços: a questão etiológica retoma a cena e a clínica médica se abre para procedimentos clínicos estrangeiros, ou seja, para o jogo clássico do (re)educar/(re)aprender. Assim, assistimos a uma situação aparentemente paradoxal: o tratamento da afasia permanece estritamente médico e o tratamento do afásico, caracterizado como de reeducação, escapa ao âmbito da Medicina.

De fato, a impossibilidade de reversão de um quadro lesional parece ter criado a exigência de instituição de uma outra clínica, com vistas menos na lesão e mais na transformação do sintoma (linguagem), em que se mesclam ações estritamente médicas (exame neurológico, medicação, cirurgia) e proposta de reeducação. No âmbito de uma clínica assim configurada, as ações - pautadas no método comportamentalista (estímuloresposta-reforçamento) - refletem o apego à causalidade, alçada aqui, para uma terapêutica da fala. Ela é impulsionada, então, por um pensamento causal no campo da ação. 
Cadernos de Estudos Lingüísticos 47(1) e (2) - Jan./Dez. 2005

Da clínica médica stricto sensu à de reeducação passa-se, portanto, da ação direta no cérebro à ação indireta ou, em outras palavras, da certeza da ação à suposição de que, indiretamente, se possam produzir mudanças no funcionamento cerebral. Deve-se concluir, assim, que não é a teoria da afasia que norteia efetivamente essa clínica nascente já que nessa mescla assiste-se à fratura entre causalidade epistemológica e causalidade terapêutica. Não é sem razão, portanto, que essa prática tenha sido abortada no espaço da Medicina e que tenha vingado em Centros de Reabilitação da Afasia.

Nesses Centros, a afasia nasce, após a Segunda Guerra Mundial, como questão clínica, quer dizer, como resposta direta à demanda de "reabilitação" . Neles, reuniram-se diversos profissionais: neurologistas (Eisenson, 1954, entre outros), psicólogos (Wepman, 1951, entre outros), psiquiatras, fonoaudiólogos (Schuell, 1965, 1974) e lingüistas (Jakobson, 1954). A congregação desses diversos pesquisadores, em torno da afasia, deu origem a enfoques interdisciplinares.

Procurei discutir, no doutorado, que nem a "reabilitação", concebida no âmbito interdisciplinar pode ser dita propriamente um campo de investigação científico ${ }^{7}$, nem a propagada postulação de interdependência entre as referidas disciplinas é (de fato) verdadeira, uma vez que a Neurologia - seu aporte teórico-clínico -é tomada como modelo a partir do qual considerações psicológicas, lingüísticas e, eu diria até, sociológicas mesclamse no processo terapêutico. Mescla que tem impedido o questionamento de procedimentos utilizados e, acima de tudo, inviabilizado a instituição de um campo teórico motivado pela clínica.

De fato, Basso (1977) e Schuell $(1965,1974)$, mentoras inequívocas do que se produziu na reabilitação da afasia, cederam ao fascínio da Neurologia. Por isso, as indagações sobre o afásico ficam circunscritas ao seu comportamento desadaptado, seja ele social, emocional ou lingüístico. Daí que todas as técnicas visam readaptá-lo. Não é de estranhar, então, que a discussão gire em torno de metodologias, técnicas e eficácia de sua aplicação; que se assista a um giro por entre disciplinas científicas e a um caminho em direção à Psicologia comportamental. Complica-se, desse modo, a dimensão da clínica da afasia já que a meta é, digamos, ortopédica: ajustamento (impossível) da fala a um suposto padrão como garantia da adaptação social/comunicativa.

Outra complicação está em que na instância da intervenção, no horizonte permanece a determinação orgânica instruindo uma técnica em que o sujeito perde $a$ vez e a voz. "Voz" (sem "vez") que deve mudar para que a comunicação seja restaurada. De fato, não é outra coisa que se pode retirar das "propostas de reabilitação" e do planejamento de ações como norte terapêutico. Propostas resumidas em "manuais e guias" que abrem espaço para que leigos (voluntários) treinados possam conduzir o tratamento de afásicos. Nesse excesso, assiste-se à diluição da clínica e da figura do terapeuta.

${ }^{6}$ Uso aspas na palavra reabilitação para indicar uma direção de tratamento que é médica (supressão de sintoma). Ela supõe, também, um "habilitar de novo" o que, no caso da afasia, é, no mínimo, como vimos e como veremos, uma questão controversa.

${ }^{7}$ Ver, também, Landi (2000). 
O que procurei mostrar, no doutorado, e que, espero, possa ser reconhecido como diferença, é uma outra concepção de clínica: aquela que dá "voz e vez" à "fala em sofrimento que faz sofrer um sujeito". Os casos clínicos que apresentei mostram uma configuração específica de clínica - de clínica de linguagem - uma que coloca em jogo: a) a singularidade de cada paciente e sua fala; b) a heterogeneidade no (de cada) caso; c) a necessária articulação entre teoria e "ações clínicas"; d) a impossibilidade, para um leigo, de conduzir um atendimento; e) o distanciamento/ruptura com propostas de reeducação.

Digo isso porque o que trouxe sobre os procedimentos de entrevista, avaliação de linguagem e direção de tratamento delineia um ponto de vista segundo o qual a clínica de linguagem é instituída, ao mesmo tempo, por uma teoria e por uma escuta particular para a fala. Nessa perspectiva, pude propor, por exemplo que, no que concerne a entrevista, a convocação do afásico e não de um informante, decorre da assunção de que, nessa clínica, a questão subjetiva é central. Note-se que, na entrevista assim configurada, "o afásico é chamado a falar" com as condições de fala que tem. Assume-se, assim, que a "entrada" na clínica de linguagem deve implicar o sujeito e $(\mathrm{m})$ seu sofrimento. Por isso, a questão da queixa e da demanda, que envolvem o sintoma na linguagem, exigem considerar que não se pode prescindir do singular para que ela - a clínica - aconteça. De fato, a discussão de casos clínicos (apresentados na tese) indicou ser preciso levar em conta sua singularidade. Estamos, então, falando de uma base comum - convocar o paciente para a entrevista - que não exclui considerações caso a caso (um familiar requerer participar; o afásico consentir ou, até mesmo, requisitar a sua presença, etc.). O que não se perde de vista é o compromisso com o afásico e sua fala, o que reclama sua presença: é a ele que se dirige a palavra desde esse momento inaugural. O que se espera é que ele tome a palavra, e a "vez", e seu malestar possa ser transformado em apelo dirigido àquele terapeuta.

$\mathrm{Na}$ avaliação de linguagem - outro passo diagnóstico - o que está em causa é o enfrentamento da fala sintomática. É nessa instância que se dá a imbricação necessária entre a "escuta na cena clínica" e a "escuta/leitura do material clínico". Isso quer dizer que, em se tratando de clínica de linguagem, essas "escutas" afetam-se mutuamente. Não foi, portanto, a partir de uma análise lingüística strictu sensu que a fala dos pacientes foi abordada na tese de doutorado. Entretanto, uma interpretação só pôde ser realizada porque orientada por uma teorização que abre espaço para a problematização de singularidades heterogêneas. Mais particularmente, teorização que não fecha a porta para um compromisso com o particular de uma fala e com as exigências de natureza propriamente clínica.

Entendo que só por isso, desdobramentos originais que não poderiam ser pensados no âmbito da Aquisição de Linguagem, puderam ocorrer. Entre eles, o reconhecimento da complexidade envolvida na presença trágica de um sujeito na linguagem, de uma nãocoincidência insuperável entre fala-escuta e da impossível "recuperação" de uma fala. Complexidades que não podem ser enfrentadas pela Aquisição da Linguagem ou pela Lingüística, dada a própria natureza de seus objetivos e metodologias. Na avaliação de

${ }^{8}$ Ver Arantes (1994, 2001), Lier-De Vitto \& Arantes (1998) e Andrade (2001). 
Cadernos de Estudos Lingüísticos 47(1) e (2) - Jan./Dez. 2005

linguagem, articulam-se o "sinto-mal" do paciente com a interpretação do terapeuta -fonte/ síntese para uma direção de tratamento.

Como se vê, a terapêutica propriamente dita está intimamente vinculada ao processo diagnóstico. Se a sua base comum implica um "deixar falar o paciente", o modo como esse "falar" se instancia é que determina a interpretação do terapeuta. Interpretação que, portanto, não se realiza à revelia do dizer do paciente mas que incide sobre essa trama significante. Se a discussão dos casos pode mostrar que não há regra ou norma para interpretar, há que se respeitar, contudo, uma condição essencial para que a interpretação não produza um efeito disruptivo, que ela não retire o paciente da condição de falante quando ele procura sustentá-la.

A apresentação dos casos também pôs a descoberto que uma clínica sempre encontra seus limites: seja no método que implementa, seja na condição subjetiva do paciente. Não se deve ignorar que, muitas vezes, limites são impostos pelas dificuldades orgânicas para a produção da fala. Não se trata, portanto, de ignorar o orgânico mas deve-se ter em conta os limites de sua determinação: para que mudanças ocorram na fala (e na posição sujeitofalante) uma outra "causalidade" tem papel decisivo. Refiro-me aqui à "causalidade clínica" instanciada no jogo da interpretação lingüística: é ela que dá fundamento à mudança que se espera venha a acontecer. Só que essa "causalidade lingüísticamente determinada" implica o contingente, o singular. Daí que ela não comporta previsibilidade mecânica. A clínica de linguagem deve levar em conta, então, o imprevisível que marca o encontro do paciente com o terapeuta e de ambos com o sintoma.

Para finalizar, gostaria de colocar em relevo o fato de que, no âmbito dessa clínica de linguagem, o Interacionismo propicia a aproximação à trama significante e a Psicanálise movimenta considerações sobre uma clínica em que o sujeito está em questão. Entretanto, procurei circunscrever a posição do Interacionismo e também a da Psicanálise. Pretendi mostrar que a abordagem da fala sintomática implica uma escuta clínica singular e que a clínica de linguagem não é clínica psicanalítica. Entendo que esse compromisso de delimitação reflete minha filiação ao Interacionismo proposto por Cláudia Lemos.

\section{REFERÊNCIAS BIBLIOGRÁFICAS}

ANDRADE, L. (2001). Os efeitos da fala como acontecimento na clínica fonoaudiológica, em Letras de Hoje, vol. 36, $n^{o}$ 3. EDIPUCRS. Porto Alegre.

ARANTES, L. (1994). O fonoaudiólogo, esse aprendiz de feiticeiro. M. F. Lier-De Vitto (org.) Fonoaudiologia: no Sentido da Linguagem. Ed. Cortez: São Paulo.

. (2001). Diagnóstico e Clínica de Linguagem. Tese de Doutoramento. LAEL-PUC/SP.

BASSO, A. (1977). Il Paziente Afasico. Guida Pratica Alla Riabilitazione. Feltrinelli Editore, Milano, $2^{\mathrm{a}}$ edição.

BENSON, D. F. \& ARDILA, A. (1996). Aphasia. A Clinical Perspective. Oxford University Press: Oxford.

EISENSON, J. (1954). Examining for Aphasia. New York: Psychological Corp.

FONSECA, S. C. (1995). Afasia: A Fala em Sofrimento. Dissertação de Mestrado. LAEL/PUC-SP. (2002). O afásico na clínica de linguagem. Tese de Doutoramento. LAEL/PUC-SP. 
FONSECA - Interacionismo, afasia e clínica de

FONSECA, S. C. \& VORCARO, A. (1998). O atendimento fonoaudiológico e psicanalítico de uma paciente que não se reconhece (é reconhecida) falante (no prelo).

FREUD, S. (1891/1987). La Afasia. Ediciones Nueva Vision. Buenos Aires.

GOLDSTEIN, K. (1933). L'analyse de l'aphasie et l'etude de l'essence du langage, in Journal de Psychologie. . (1948). Transtornos del Lenguaje. Las Afasias. Su Importancia para la Medicina y la Teoria del Lenguaje. Editorial Científico Médica. Barcelona.

HENRY, P. (1990). Os fundamentos teóricos da analise automatica do discurso de Michel Pêcheux (1969). In: Gadet, F. e Hak, T. (orgs.). Por uma análise automática do discurso. Editora da Unicamp, Campinas.

JACKSON, J. H. (1866/1932). Notes on the Physiology and Pathology of Language, in Selected Writings of John Hughlings Jackson, vol. 2. Hodder and Stoughton Limited. London. (1884/1932). Evolution and Dissolution of the Nervous System, in Selected Writings of John Hughlings Jackson, vol. 2. Hodder and Stoughton Limited. London.

JAKOBSON, R. (1954/1988). Dois Aspectos da Linguagem e Dois Tipos de Afasia, in Lingüística e Comunicação. Cultrix: São Paulo.

LANDI, R. (2000). Sob Efeito da Afasia: A Interdisciplinaridade como Sintoma nas Teorizações. Dissertação de Mestrado, LAEL/PUC-SP, São Paulo.

LEMOS, C.T.G. (1982). Sobre a aquisição da linguagem e seu dilema (pecado) original. Boletim da Abralin, vol. 3. Editora da Universidade Estadual de Pernambuco. Recife. . (1986). A sintaxe no espelho, em Cadernos de Estudos Lingüísticos, vol. 10. UNICAMP. Campinas. (1992). Los Procesos Metafóricos Y Metonímicos como Mecanismos de Cambio, in Substratum, vol.1, $n^{\circ}$ 1. Meldar: Barcelona.

. (1995). Língua e Discurso na Teorização Sobre Aquisição da Linguagem, in Letras de Hoje, vol. 30, $n^{o}$ 4. Editora da Puc-RS. Porto Alegre.

(1996). A Poética entre a Fala e a Língua, in Jornadas Internas de 1996. Tema: Lacan no Simbólico. Escola Lacaniana de Psicanálise de Campinas.

. (2002). Das viscissitudes da fala da criança e de sua investigação. In Cadernos de Estudos Lingüísticos, $n^{\circ}$ 42. UNICAMP/Campinas.

Lier-De Vitto, M.F. (1995). Língua e Discurso: à luz dos monólogos da criança. Letras de Hoje, vol. 30, $n^{o} 4$. EDIPUC -RS: Porto Alegre. (2002e). Patologias da linguagem: sobre as 'viscissitudes de falas sintomáticas'. Texto Inédito.

Lier-De VitTo, M. F. \& ARANTES, L. (1998). Sobre os Efeitos da Fala da Criança: da Heterogeneidade desses Efeitos. Letras de Hoje, vol. 33, $n^{\circ}$ 2. EDIPUC-RS: Porto Alegre.

LURIA, A.R. (1947). A Afasia Traumática. Mouton, The Hague. (1974). El Cerebro em accion. Editorial Fontanella S.A. Barcelona

PÊCHEUX, M. (1969). Análise automática do discurso, em F. Gadet e T. Hak (orgs) (1990) Por uma Análise Automática do Discurso - Uma Introdução à Obra de Michel Pêcheux. Editora da UNICAMP. Campinas.

RUBINSTEIN, A.M. (1996). El concepto de síntoma en Freud, em Diversidad del síntoma. Edita EOL. Argentina.

SAUSSURE, F. (1916/1991). Curso de Lingüística Geral. Editora Cultrix. São Paulo.

SCHUELL, H. (1965/1976). Afasia en Adultos según Schuell. Diagnóstico, Prognóstico y Tratamento. Editorial Panamericana.

. (1974). Aphasia Theory and Therapy. Selected Lectures and Papers of Hildred Schuell. The Macmillan Press Ltd. London.

WEPMAN, J.M. (1951). Recovery from Aphasia. Ronald: New York. 